\title{
EVALUASI KINERJA SIMPANG DI KOTA CIMAHI DENGAN METODE SIMULASI
}

\author{
Ferry Rusgiyarto \\ Program Studi Teknik Sipil, Fakultas Teknik \\ Universitas Jenderal Achmad Yani \\ Jln. Terusan Jenderal Sudirman \\ PO Box 148, Cimahi \\ ferry.rusgiarto@lecture.unjani.ac.id \\ Gavinella Desijayanti \\ Program Studi Teknik Sipil, Fakultas Teknik \\ Universitas Jenderal Achmad Yani \\ Jln. Terusan Jenderal Sudirman \\ PO Box 148, Cimahi \\ gavinella.desi.jayanti@gmail.com
}

\author{
Hanafi \\ Program Studi Teknik Sipil, Fakultas Teknik \\ Universitas Jenderal Achmad Yani \\ Jln. Terusan Jenderal Sudirman \\ PO Box 148, Cimahi \\ hanafi@lecture.unjani.ac.id \\ Widi Suci Islami \\ Program Studi Teknik Sipil, Fakultas Teknik \\ Universitas Jenderal Achmad Yani \\ Jln. Terusan Jenderal Sudirman \\ PO Box 148, Cimahi \\ widisuciislami@gmail.com
}

\begin{abstract}
The intersection is a meeting place for vehicle flows from several roads and as a place for vehicles to change the direction of traffic movement. In this study an observation was made on the ARMED Intersection and the Taman Sudirman Intersection, located in Cimahi City, which have experienced traffic problems. A simulation was carried out at these intersections, using the VISSIM PTV software, and taking into account the behavior of the driver. The results of this study indicate that for micro analysis, the delay and speed criteria are more suitable for use than the degree of saturation criteria.
\end{abstract}

Keywords: intersection, traffic, delay, speed, degree of saturation

\begin{abstract}
Abstrak
Simpang merupakan tempat bertemunya arus kendaraan dari beberapa ruas jalan dan sebagai tempat kendaraan melakukan perubahan arah pergerakan lalu lintas.Pada studi ini dilakukan pengamatan terhadap Simpang ARMED dan Simpang Taman Sudirman Kota Cimahi, yang telah mengalami masalah lalu lintas. Suatu simulasi dilakukan pada simpang-simpang tersebut, dengan perangkat lunak PTV VISSIM, dengan mempertimbangkan perilaku pengemudi. Hasil studi ini menunjukkan bahwa untuk analisis mikro, kriteria-kriteria tundaan dan kecepatan lebih sesuai untuk digunakan daripada kriteria derajat kejenuhan.
\end{abstract}

Kata-kata kunci: simpang, lalu lintas, tundaan, kecepatan, derajat kejenuhan

\section{PENDAHULUAN}

Kemacetan sudah menjadi masalah umum di wilayah perkotaan, khususnya di persimpangan yang dekat dengan pusat keramaian, seperti kantor dan pasar. Kemacetan ini biasanya disebabkan oleh berbagai faktor, yang salah satunya adalah bertambahnya jumlah penduduk yang berimplikasi pada meningkatnya mobilisasi di wilayah perkotaan (Algifar, 2017; Dinata et al., 2017).

Kota Cimahi adalah suatu kota dengan pertumbuhan jumlah penduduk yang sangat cepat. Simpang ARMED dan Simpang Taman Sudirman yang berada di Kota Cimahi, Jawa Barat, mempunyai pergerakan lalu lintas yang tinggi, terutama pada jam sibuk. Hal tersebut 
terjadi karena Simpang ARMED dengan Simpang Taman Sudirman adalah persimpangan yang saling berkaitan dengan jarak antarsimpang yang pendek, ditambah dengan kondisi wilayah sekitarnya yang merupakan kompleks perkantoran dan sekolah.

Permodelan transportasi dapat digunakan untuk melihat pengaruh kebijakan atau rencana pengembangan terhadap jaringan transportasi di suatu wilayah (Ansusanto dan Tanggu, 2016; Aryandi, 2014). Penelitian ini menggunakan perangkat lunak berbasis model mikrosimulasi untuk menentukan kinerja antarsimpang, tahapan kegiatan seperti pada Gambar 1.

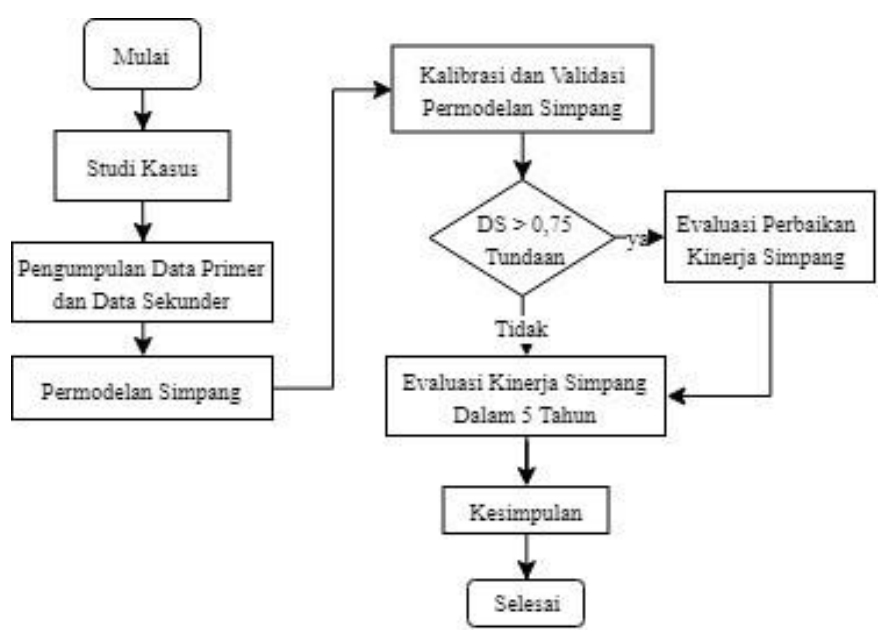

Gambar 1 Metodologi Analisis

\section{DATA DAN ANALISIS}

\section{Data Primer}

Data primer dalam penelitian ini diperlukan untuk proses kalibrasi dan validasi. Data primer yang digunakan pada studi ini adalah sebagai berikut:

1) Data Geometrik Simpang; Data ini berisi mengenai kondisi geometrik jalan yang akan ditinjau. Survei geometrik simpang dilakukan di 2 simpang yang dimulai dari Simpang ARMED yang berada di Jln. HMS Mintaredja, SH, dengan Jln. Baros dan Simpang Taman Sudirman yang berada di Jln. Baros dengan Jln. Jenderal Sudirman, Kota Cimahi. Kondisi geometrik pada kedua simpang tersebut dapat dilihat pada Gambar 2.

2) Data Volume Lalu Lintas; Data yang diambil di 2 simpang. Dari hasil observasi yang dilakukan pada jam sibuk diperoleh rekapitulasi volume kendaraan jam puncak, seperti yang terdapat pada Tabel 1.

3) Data Kecepatan dan Data Tundaan; Data yang didapat merupakan hasil observasi. Tabel 2 dan Tabel 3 merupakan data rekapitulasi kecepatan rata-rata kendaraan dan data rekapitulasi tundaan untuk setiap jenis kendaraan. 


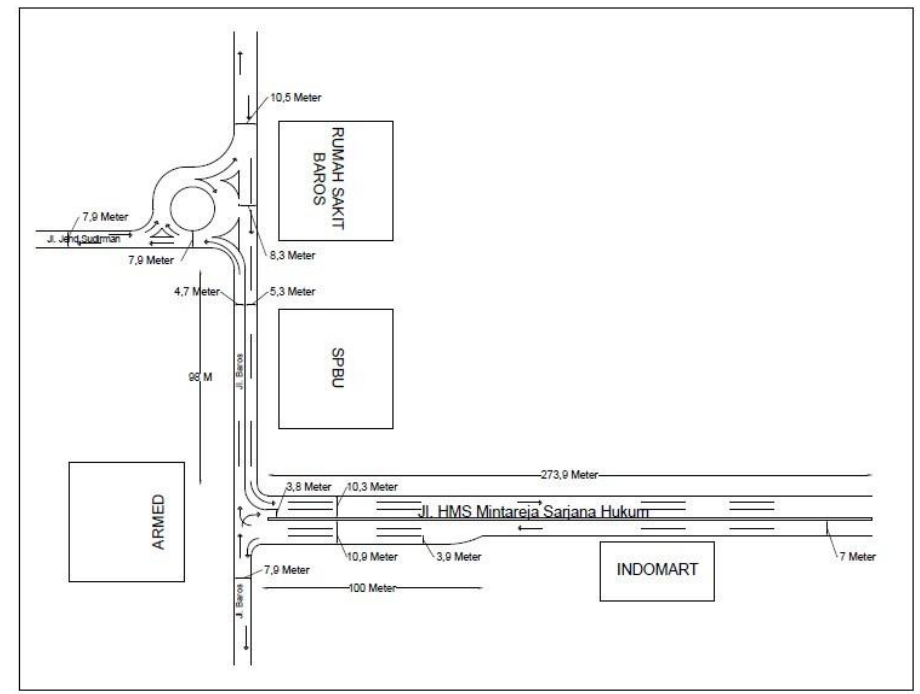

Gambar 2 Geometrik Simpang

Tabel 1 Rekapitulasi Volume Kendaraan Puncak

\begin{tabular}{|c|c|c|c|c|c|c|}
\hline \multirow{3}{*}{ Simpang } & \multirow{3}{*}{ Arah Simpang } & \multicolumn{5}{|c|}{ Total Volume Lalu Lintas Kendaraan } \\
\hline & & $16.00-17.00$ & $16.15-17.15$ & $16.30-17.30$ & $16.45-17.45$ & $17.00-18.00$ \\
\hline & & WIB & WIB & WIB & WIB & WIB \\
\hline \multirow[t]{5}{*}{ ARMED } & Jln. HMS-Jln. Baros G & 2652 & 2447 & 2214 & 1855 & 1694 \\
\hline & Jln. HMS-Jln. Baros H & 1862 & 1762 & 1722 & 1671 & 1670 \\
\hline & Jln. Baros H-Jln. Baros G & 1453 & 1298 & 1188 & 1151 & 1219 \\
\hline & Jln. Baros H-Jln. HMS & 342 & 342 & 330 & 321 & 297 \\
\hline & Jln. Baros G-Jln. HMS & 2593 & 2413 & 2041 & 1756 & 1541 \\
\hline \multicolumn{2}{|c|}{ Total Volume } & 8902 & 8262 & 7495 & 6754 & 6421 \\
\hline Taman & Jln. Jensud-Jln. Baros G & 933 & 935 & 943 & 996 & 951 \\
\hline \multirow[t]{5}{*}{ Sudirman } & Jln. Jensud-Jln. Baros F & 178 & 148 & 153 & 128 & 105 \\
\hline & Jln. Baros F- Jln. Baros G & 1661 & 1650 & 1570 & 1538 & 1606 \\
\hline & Jln. Baros F- Jln. Jensud & 231 & 221 & 200 & 188 & 179 \\
\hline & Jln. Baros G- Jln. Baros F & 1640 & 1580 & 1573 & 1499 & 1327 \\
\hline & Jln. Baros G- Jln. Jensud & 2465 & 2242 & 2053 & 1907 & 1723 \\
\hline \multicolumn{2}{|l|}{ Total Volume } & 7108 & 6776 & 6492 & 6257 & 5891 \\
\hline \multicolumn{2}{|c|}{ Total (Simpang 1+2) } & 16010 & 15038 & 13987 & 13011 & 12312 \\
\hline
\end{tabular}

Tabel 2 Rekapitulasi Kecepatan Kendaraan

\begin{tabular}{lccc}
\hline \multirow{2}{*}{ Keterangan } & \multicolumn{2}{c}{$\begin{array}{c}\text { Kecepatan Perjalanan } \\
(\mathrm{km} / \mathrm{jam})\end{array}$} & $\begin{array}{c}\text { Kecepatan } \\
\text { Rata-Rata } \\
(\mathrm{km} / \mathrm{jam})\end{array}$ \\
\cline { 2 - 3 } & Minimum & Maksimum & 28 \\
Kendaraan Pribadi & 18 & 41 & 22 \\
Minibus & 18 & 25 & 27 \\
Pick Up & 17 & 37 & 29 \\
Bus Sedang & 17 & 44 & 20 \\
Bus Besar & 17 & 23 & 27 \\
Truk Sedang & 21 & 39 & 22 \\
Truk Besar & 17 & 35 & 32 \\
Sepeda Motor & 18 & 55 & \\
\hline
\end{tabular}

\section{Data Sekunder}

Data sekunder yang digunakan pada studi ini dimaksudkan untuk melengkapi informasi pada analisis. Data sekunder tersebut adalah: 
1) Data Lalu Lintas Kendaraan di Gardu Tol Baros Cimahi; Tabel 4 adalah data lalu lintas keluar dan masuk kendaraan di Gerbang Tol Baros Cimahi pada bulan Januari 2019 dalam satuan kendaraan/hari. Volume terbesar lalu lintas kendaraan yang keluar dan masuk ke Gerbang Tol Baros terjadi pada hari Senin.

2) Data Pertumbuhan Lalu Lintas; Perkiraan pertumbuhan lalu lintas untuk 5 tahun mendatang didapat dari analisis tingkat pertumbuhan lalu lintas dengan meninjau data jumlah kendaraan mulai dari tahun 2013 sampai dengan tahun 2018. Data pertumbuhan lalu lintas ersebut dapat dilihat pada Tabel 5.

Tabel 3 Rekapitulasi Tundaan untuk Setiap Lengan Jalan

\begin{tabular}{lr}
\hline Batasan Tundaan & Waktu Tundaan Rata-Rata (detik) \\
\hline Jln. HMS ke Jln. Baros G & 5,61 \\
Jln. Baros H ke Jln. HMS & 10,02 \\
Jln. Baros H ke Jln. Baros G & 2,69 \\
Jln. HMS ke Jln. Baros H & 3,06 \\
Jln. Baros G ke Jln. Jenderal Sudirman & 10,50 \\
Jln. Baros G ke Jln. HMS & 2,80 \\
Jln. Baros G ke Jln. Baros F & 8,65 \\
Jln. Jenderal Sudirman ke Jln. Baros G & 2,25 \\
Jln. Jenderal Sudirman ke Jln. Baros F & 2,23 \\
Jln. Baros F ke Jln. Baros G & 5,28 \\
Jln. Baros F ke Jln. Jenderal Sudirman & 5,86 \\
Jln. HMS POM ke HMS U-Turn & 7,20 \\
Jln. HMS ke Jln. HMS (Pusdikpom) & 1,96 \\
\hline
\end{tabular}

Tabel 4 Data Gardu Gerbang Tol Baros 1 dan Baros 2

\begin{tabular}{clcclc}
\hline No. & Hari & $\begin{array}{c}\text { Lalu Lintas Kendaraan } \\
\text { (kend/hari) }\end{array}$ & No. & Hari & $\begin{array}{c}\text { Lalu Lintas Kendaraan } \\
\text { (kend/hari) }\end{array}$ \\
\hline 1 & Selasa & 63.985 & 16 & Rabu & 49.392 \\
2 & Rabu & 52.539 & 17 & Kamis & 59.699 \\
3 & Kamis & 63.949 & 18 & Jumat & 59.620 \\
4 & Jumat & 62.993 & 19 & Sabtu & 59.172 \\
5 & Sabtu & 61.783 & 20 & Minggu & 59.342 \\
6 & Minggu & 61.575 & 21 & Senin & 64.680 \\
7 & Senin & 64.999 & 22 & Selasa & 60.613 \\
8 & Selasa & 64.940 & 23 & Rabu & 47.331 \\
9 & Rabu & 54.936 & 24 & Kamis & 59.551 \\
10 & Kamis & 63.978 & 25 & Jumat & 58.312 \\
11 & Jumat & 48.789 & 26 & Sabtu & 59.703 \\
12 & Sabtu & 61.663 & 27 & Minggu & 61.014 \\
13 & Minggu & 60.640 & 28 & Senin & 64.170 \\
14 & Senin & 64.538 & 29 & Selasa & 61.242 \\
15 & Selasa & 59.589 & 30 & Rabu & 48.894 \\
\hline
\end{tabular}

Sumber: PT Jasamarga (Persero) Tbk (2019)

Tabel 5 Data Pertumbuhan Lalu Lintas

\begin{tabular}{ccc}
\hline Tahun & $\begin{array}{c}\text { Jumlah Kendaraan } \\
\text { (kend/tahun) }\end{array}$ & $\mathrm{i}(\%)$ \\
\hline 2013 & 6.654 .940 & \\
2014 & 6.780 .286 & 1,88 \\
2015 & 6.907 .077 & 1,87 \\
\hline Sumber: PT Jasamarga (Persero) & Tbk (2019)
\end{tabular}




\section{HASIL DAN PEMBAHASAN}

\section{Simulasi Pemodelan}

Pemodelan yang dilakukan pada penelitian ini adalah pemodelan mikrosimulasi yang dimulai dengan membuat network model atau jaringan jalan, memasukkan data lalu lintas kendaraan, kecepatan kendaraan, komposisi kendaraan, serta kalibrasi dan validasi model. Pada Gambar 3 ditampilkan visualisasi pemodelan VISSIM kondisi eksisting pada Simpang ARMED dan Simpang Taman Sudirman.

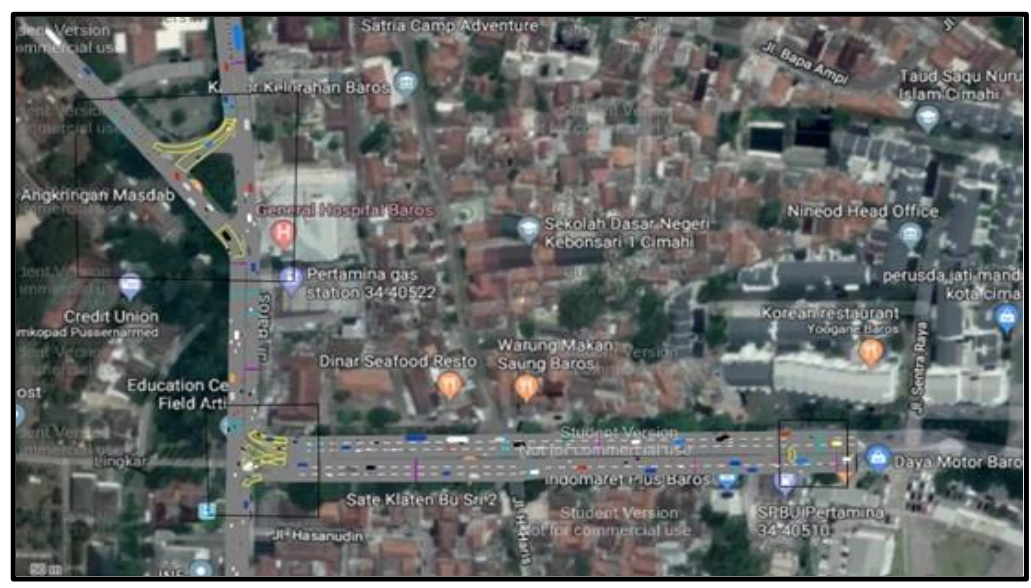

Gambar 1 Visualisasi Model Jaringan dengan VISSIM

Kalibrasi model pada perangkat lunak PTV VISSIM 11.0 dilakukan untuk mendapatkan kesesuaian antara model observasi dan model simulasi dengan mengubah parameter perilaku pengemudi sehingga model mirip dengan kondisi lapangan. Penyesuaian nilai pada kalibrasi model ditunjukkan pada Tabel 6.

Tabel 6 Penyesuaian Perilaku Pengemudi

\begin{tabular}{|c|c|c|c|}
\hline Variabel & Parameter Driving Behaviour & Sebelum & Sesudah \\
\hline \multirow{4}{*}{$\begin{array}{l}\text { Car } \\
\text { Following }\end{array}$} & $\begin{array}{l}\text { Average standstill distance } \\
\text { (jarak antarkendaraan pada saat berhenti di } \\
\text { simpang) }\end{array}$ & 2 meter & 0,06 meter \\
\hline & $\begin{array}{l}\text { Additive part of safety distance } \\
\text { (koefisien penambah jarak aman) }\end{array}$ & 2 & 0,6 \\
\hline & $\begin{array}{l}\text { Multiplicative part of safety distance } \\
\text { (koefisien pengali jarak aman) }\end{array}$ & 3 & 1 \\
\hline & No of observed vehicle & 2 & 2 \\
\hline \multirow[t]{4}{*}{$\begin{array}{l}\text { Lane } \\
\text { Change }\end{array}$} & General Beahviour & $\begin{array}{l}\text { Free lane } \\
\text { selection }\end{array}$ & $\begin{array}{l}\text { Free lane } \\
\text { selection }\end{array}$ \\
\hline & Minimum headway & 0,5 meter & 0,5 meter \\
\hline & $\begin{array}{l}\text { Desired position at free flow } \\
\text { (lajur jalan yang diinginkan oleh pengendara) }\end{array}$ & $\begin{array}{l}\text { Midle of lane } \\
\text { (lajur tengah) }\end{array}$ & $\begin{array}{c}\text { Any } \\
\text { (di mana pun/acak) }\end{array}$ \\
\hline & $\begin{array}{l}\text { Overtake on same lane: on left and on right } \\
\text { (dapat menyiap dari lajur mana pun) }\end{array}$ & off & on \\
\hline \multirow[t]{2}{*}{ Lateral } & $\begin{array}{l}\text { Distance standing }(\text { at } 0 \mathrm{~km} / \mathrm{h})(\mathrm{m}) \\
\text { (jarak antarkendaraan pada saat berhenti) }\end{array}$ & 1 meter & 0,20 meter \\
\hline & $\begin{array}{l}\text { Distance driving (at } 50 \mathrm{~km} / \mathrm{h})(\mathrm{m}) \\
\text { (jarak antarkendaraan pada saat mendekati } \\
\text { mulut simpang) }\end{array}$ & 1 meter & 0,40 meter \\
\hline
\end{tabular}


Validasi adalah proses untuk menguji kebenaran pemodelan. Pada pemodelan menggunakan VISSIM ini, proses kalibrasi telah dilakukan. Validasi hasil kalibrasi kemudian diuji dengan metode Geoffrey E. Havers (GEH). Validasi ini membutuhkan parameter, seperti volume lalu lintas. Formulasi GEH merupakan rumus statistika hasil modifikasi model Chi-squared, dengan menggabungkan perbedaan antara nilai relatif dan nilai mutlak.

$$
G E H=\sqrt{\frac{(Q \text { simulazed }-Q \text { observed })}{0,5 x(Q \text { simulazed }+Q \text { observed })}}
$$

Berdasarkan perhitungan, validasi untuk volume lalu lintas untuk semua pendekat di masingmasing periode sudah memenuhi syarat, karena bernilai lebih kecil dari 5, sehingga model simulasi dapat diterima dan digunakan untuk analisis kinerja lalu lintas dan menguji alternatif perbaikan yang diidentifikasikan.

Analisis kinerja simpang untuk 5 tahun mendatang dilakukan untuk memperkirakan kondisi kelayakan jalan dan tingkat kinerja simpang di 5 tahun mendatang, berdasarkan nilai derajat kejenuhan (DS) dan tundaan (D), sesuai dengan standar Manual Kapasitas Jalan Indonesia (MKJI) 1997. Untuk dapat mengetahui kinerja simpang pada tahun 2024 perlu ditentukan pertumbuhan volume lalu lintas, agar dapat diperkirakan arus lalu lintas yang melewati simpang tersebut pada 5 tahun mendatang. Angka pertumbuhan yang diperoleh adalah $2,6 \%$.

Hasil simulasi kondisi eksisting menunjukkan bahwa nilai derajat kejenuhan pada jam sibuk, hari Senin pukul 16.00-17.00, melebihi angka 0,75. Untuk itu, diperlukan perbaikan untuk meningkatkan kualitas simpang. Alternatif penanganan yang diuji dalam studi kasus ini adalah: (a) perencanaan sistem satu arah pada Simpang Taman Sudirman dengan pelebaran jalan; dan (b) perencanaan lampu lalu lintas di Simpang ARMED.

Hasil simulasi dengan beberapa kondisi, yaitu kondisi eksisting dan kondisi 5 tahun mendatang menunjukkan terjadi perubahan kinerja pada Simpang ARMED dan Simpang Taman Sudirman, yang salah satu indikasinya adalah kemacetan di simpang. Perbandingan kondisi eksisting, kondisi 5 tahun mendatang, dan alternatif penanganan dengan menggunakan parameter waktu tundaan, waktu tempuh, kecepatan tempuh, dan derajat kejenuhan adalah sebagai berikut:

a) Perbandingan tundaan kendaraan dapat dilihat pada Gambar 4 dan Gambar 5, yang menunjukkan bahwa tundaan pada setiap kondisi mengalami perbedaan. Kondisi alternatif 1 menunjukkan penurunan tundaan dibandingkan dengan kondisi eksisting, sedangkan tundaan untuk kondisi alternatif 2 mengalami kenaikan dibandingkan dengan kondisi eksisting pada setiap simpang. Perbandingan pada kondisi 5 tahun mendatang menunjukkan hal yang serupa dengan kondisi tahun 2019.

b) Perbandingan waktu tempuh dan kecepatan tempuh dengan jarak tempuh sebesar 480 meter dapat dilihat pada Gambar 6 dan Gambar 7. Kondisi alternatif 1 menunjukkan penurunan waktu tempuh, sehingga kecepatan bertambah besar dengan kondisi 
eksisting, sedangkan untuk kondisi alternatif 2 terjadi kenaikan pada waktu tempuh akan tetapi kecepatan mengalami penurunan pada kondisi eksisting. Kondisi pada 5 tahun mendatang sama halnya dengan kondisi eksisting tahun 2019.

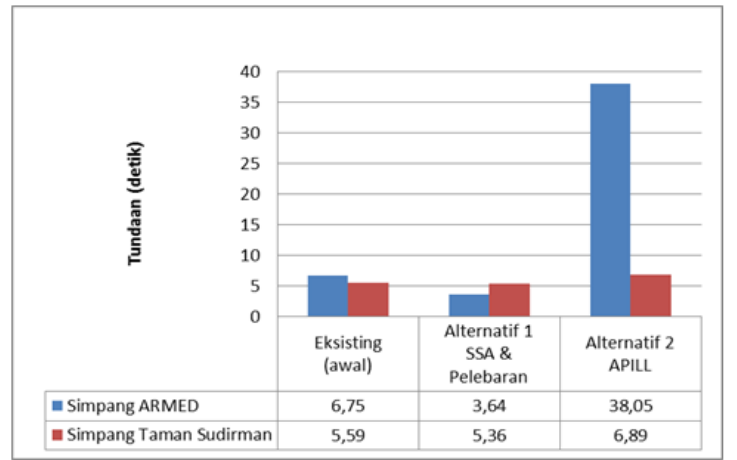

Gambar 4 Perbandingan Waktu Tundaan pada Tahun 2019

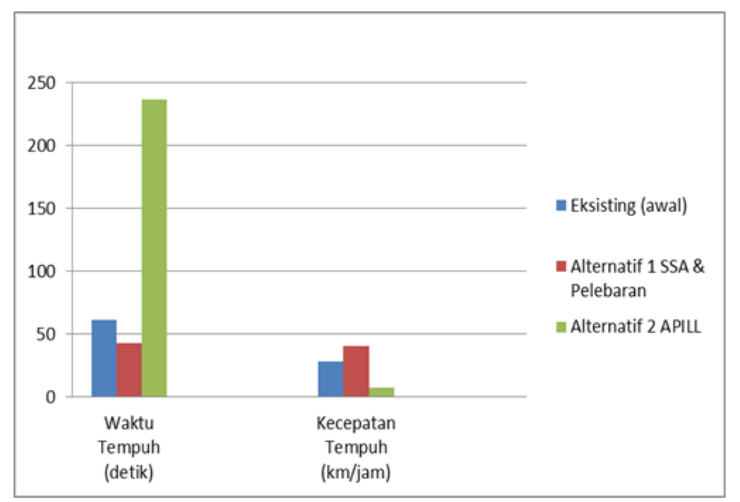

Gambar 6 Perbandingan Waktu Tempuh dan Kecepatan Tempuh pada Tahun 2019

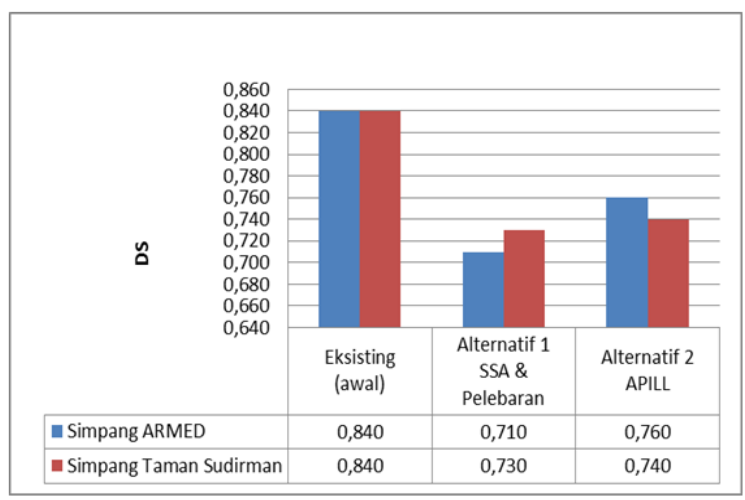

Gambar 8 Diagram Penurunan Tundaan Kendaraan Bangkitan dengan Alternatif Solusi

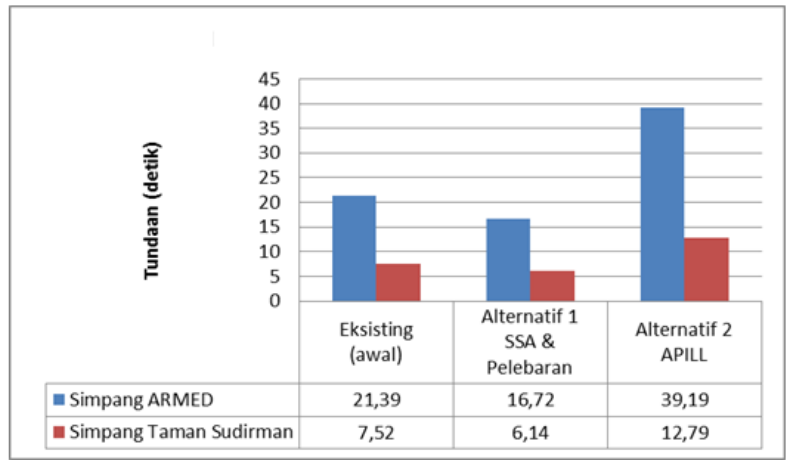

Gambar 5 Perbandingan Waktu Tundaan pada Tahun 2024

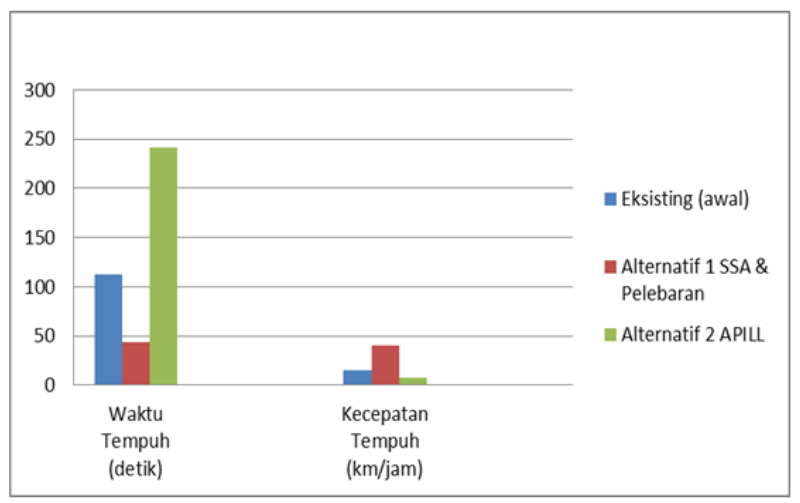

Gambar 7 Perbandingan Waktu Tempuh dan Kecepatan Tempuh pada Tahun 2024

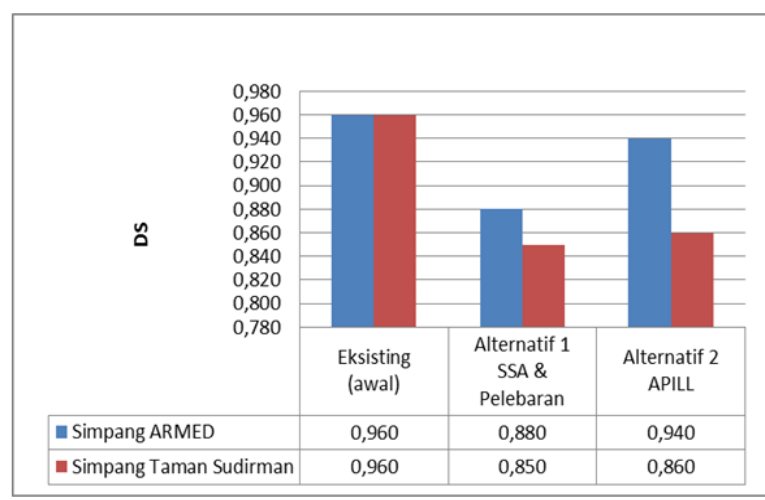

Gambar 9 Diagram Persentase Penurunan Tundaan Kendaraan 
c) Perbandingan derajat kejenuhan dapat dilihat pada Gambar 8 dan Gambar 9. Nilai derajat kejenuhan pada setiap kondisi mengalami perbedaan. Pada eksisting tahun 2019, untuk kondisi alternatif 1, terjadi penurunan nilai derajat kejenuhan sebesar 0,13 atau 15,5\% pada Simpang ARMED, sedangkan pada Simpang Taman Sudirman terjadi penurunan sebesar 0,11 atau 13,1\%. Pada kondisi alternatif 2, derajat kejenuhan mengalami penurunan sebesar 0,08 atau 9,5\% pada Simpang ARMED, dan pada Simpang Taman Sudirman juga mengalami penurunan sebesar 0,1 atau 11,9\%. Hal serupa juga terjadi untuk kondisi 5 tahun mendatang.

\section{KESIMPULAN}

Dari studi ini dapat ditarik kesimpulan sebagai berikut:

1) Volume lalu lintas pada kondisi eksisting, pada jam puncak di sore hari pukul 16.00 17.00 WIB, adalah 16.010 kendaraan, tundaan rata-rata sebesar 6,17 detik, dan waktu tempuh rata-rata sebesar 61,42 detik; sedangkan volume lalu lintas pada kondisi 5 tahun mendatang, dengan angka pertumbuhan lalu lintas sebesar 2,6\%, adalah 18.202 kendaraan, tundaan rata-rata sebesar 14,46 detik, dan waktu tempuh rata-rata sebesar 112,59 detik;

2) Solusi penanganan dengan sistem satu arah dan pelebaran berhasil meningkatkan kinerja lalu lintas pada Simpang ARMED dan Simpang Taman Sudirman; dan

3) Penggunaan parameter derajat kejenuhan untuk kriteria perbaikan menunjukkan bahwa penggunaan APILL dapat memperbaiki kinerja simang, tetapi berlawanan dengan tundaan dan kecepatan, sehingga untuk analisis mikro, kriteria-kriteria tundaan dan kecepatan lebih sesuai dibandingkan dengan derajat kejenuhan.

\section{DAFTAR PUSTAKA}

Algifar. 2017. Analisis Mikro-Simulasi Lalu Lintas Pada Rencana Pengoperasian Underpass di Simpang Mandai Makassar. Skripsi tidak dipublikasikan. Makassar: Universitas Hasanuddin.

Ansusanto, J.D. dan Tanggu, S. 2016. Analisis Kinerja dan Manajemen pada Simpang dengan Derajat Kejenuhan Tinggi. Jurnal Ilmiah Dinamika Rekayasa, 12 (2): 79-86.

Aryandi, R.D. 2014. Penggunaan Software VISSIM untuk Analisis Simpang Bersinyal. Tugas Akhir tidak diterbitkan. Yogyakarta: Program Studi Teknik Spil dan Lingkungan, Fakultas Teknik, Universitas Gadjah Mada.

Dinata, W.A., Erwan, K., dan Sumiyattinah. 2017. Analisis Kinerja Simpang Tiga pada Jalan Komyos Sudarso-Jalan Umuthalib Kota Pontianak. Jurnal Mahasiswa Teknik Sipil Universitas Tanjungpura, 4 (4): 1-9.

Direktorat Jenderal Bina Marga. 1997. Manual Kapasitas Jalan Indonesia. Jakarta. 